\title{
Reflexões sobre a educação do campo
}

\author{
e a Revolução Verde
}

\section{Reflections on field education and the Green Revolution \\ Reflexiones sobre la educación del campo}

\author{
y la revolución verde
}

Ana Lúcia Pereira

Universidade Estadual de Ponta Grossa (UEPG), Ponta Grossa/PR - Brasil

Fábio Antonio Gabriel

Universidade Estadual de Ponta Grossa (UEPG), Ponta Grossa/PR - Brasil

Reginaldo Motta de Souza

Colégio Estadual Edith de Souza Prado de Oliveira, em Santo Antônio da Platina/PR - Brasil

\begin{abstract}
Resumo
O presente artigo tem como objetivo apresentar algumas reflexões sobre a temática educação no campo após o advento da Revolução Verde, que resultou em graves traumas, cujas consequências afetaram a vida campesina na medida em que dizimaram a agricultura familiar praticada pelos pequenos agricultores. A pequena agricultura perde seu espaço diante do modelo de agronegócio, vigente na sociedade atual que descaracteriza as condições de igual competitividade entre grandes e pequenos agricultores. Por meio de pesquisa bibliográfica, busca-se problematizar a situação do pequeno proprietário que, por the ser usurpada a condição de manter sua pequena propriedade, não encontra alternativa, a não ser aquela de se tornar empregado do grande latifundiário. Como resultado do estudo, destaca-se uma possível mudança para tal quadro, que pode ser empreendida por intermédio da educação. Assim, propõe-se uma educação entendida como mediadora filosófica e política da população campesina, com a possibilidade de (re)estruturação e preservação da agricultura familiar como lócus de vida, cultura de e viabilidade econômica.
\end{abstract}

Palavras-chave: Educação do campo, Agricultura familiar, Comunidades rurais, Agronegócio

\begin{abstract}
This paper aims to present some reflections on the theme of field education after the advent of the Green Revolution that has resulted in serious traumas, which consequences have affected the peasant life when decimating family farming practiced by small farmers. Small-scale agriculture loses its space in the face of the agribusiness model in current society that deprives the conditions of equal competitiveness between large and small farmers. Through a bibliographical research, we have sought to problematize the situation of the small landowner who has no alternative, except to become an employee of the large landowner, due to the usurpation of the condition of maintaining his/her small property. As a result of the study, we highlight a possible change for such situation, which can be undertaken through education. Thus, we propose an education that is understood as a
\end{abstract}

Revista Educação Online, Rio de Janeiro, n. 26, set-dez 2017, p. 66-79 
philosophical and political mediator of the peasant population, with the possibility of (re)structuring and preserving family agriculture as locus of life, culture and economic viability.

Keywords: Field education, Family farming, Rural communities, Agribusiness.

\section{Resumen}

El presente artículo tiene como objetivo presentar algunas reflexiones sobre la temática educación en el campo tras el advenimiento de la Revolución Verde, que resultó en graves traumas, cuyas consecuencias afectaron a la vida campesina en la medida en que destruyeron la agricultura familiar practicada por los pequeños agricultores. La pequeña agricultura pierde su espacio ante el modelo de agronegocio, vigente en la sociedad actual que fragmenta las condiciones de igual competitividad entre grandes y pequeños agricultores. Por medio de investigación bibliográfica, se busca problematizar la situación del pequeño propietario que, por serle usurpada la condición de mantener su pequeña propiedad, no encuentra alternativa, a no ser aquella de convertirse en empleado del gran latifundista. Como resultado del estudio, se destaca un posible cambio a tal cuadro, que puede ser emprendido por intermedio de la educación. Así, se propone una educación que sea entendida como mediadora filosófica y política de la población campesina, con la posibilidad de (re) estructuración y preservación de la agricultura familiar como locus de vida, cultura de y viabilidad económica.

Palabras clave: Educación del campo, Agricultura familiar, Comunidades rurales, Agronegocio.

\section{Fundamentos divergentes entre a agricultura familiar e o agronegócio ${ }^{1}$}

Este artigo objetiva aprofundar estudos a respeito da maneira como o meio rural se transforma e interage, norteado por parâmetros do agronegócio; ou seja, pela forma de produção que privilegia a produção em larga escala, a monocultura, em detrimento da pequena propriedade tão sacrificada. Investigam-se os meandros das condições socioculturais, econômicas e educacionais das comunidades rurais, historicamente tão prejudicadas pelo modo de produção agrícola em curso no campo. Instala-se, na realidade, uma dicotomia entre o agronegócio e a agricultura familiar, prevalecendo, com isso, muitas vezes, o direito "de quem pode mais".

A Revolução Verde se destaca como um processo de modernização agrícola que "[...] teve início no período desenvolvimentista do segundo pós-guerra, atingindo seu auge na década de 1970" (SCHNEIDER; ESCHER, 2011, p. 204). Nesse período, a indústria de armamentos, para manter seus lucros, voltou-se à agricultura

\footnotetext{
${ }^{1}$ A elaboração deste artigo contou com apoio financeiro da Capes (Coordenação de Aperfeiçoamento de Pessoal de Nível Superior) e da Fundação Araucária.
}

Revista Educação Online, Rio de Janeiro, n. 26, set-dez 2017, p. 66-79 
e todo um aparato tecnológico foi utilizado para melhorar a produção com o slogan de acabar com a fome no mundo.

A marca desse processo é o agronegócio em forma de latifúndio, de monocultura, em que se privilegia a produção em massa com sementes geneticamente modificadas, os transgênicos. Através da mecanização e da racionalização da força de trabalho, com o objetivo de produzir em larga escala, possibilita-se a exportação. Como efeito, tem-se uma grave exclusão social no campo, entre outros males, sobretudo pela crítica situação que leva à perda da biodiversidade. "A modernização na agricultura, por meio da Revolução Verde, melhorou os índices de produtividade agrícola pela substituição dos moldes de produção locais ou tradicionais por um conjunto de práticas tecnológicas homogêneas" (PERESTRELO; MARTINS, 2003, p. 39).

Como ressaltam Andrades e Ganimi (2007, p. 44), a Revolução Verde não pode ser observada de forma simplista, apenas como "[...] um avanço técnico para aumentar a produtividade, mas também existe uma intencionalidade inserida dentro de uma estrutura e de um processo histórico". Por isso, é necessário compreender o processo desencadeado pela Revolução Verde, com base no contexto do final da Segunda Guerra, quando instituições privadas viram na agricultura um meio para a reprodução do capital (ANDRADES; GANIMI, 2007).

A Revolução Verde teve como principais beneficiários os grandes produtores e a indústria estrangeira, deixando de fora a agricultura de subsistência (SCHNEIDER; ESCHER, 2011). O processo desencadeado por ela teve como meta o lucro e instaurou uma hegemonia agrária. Apesar do relativo sucesso quanto à produtividade, "[...] esse modelo reproduziu as desigualdades distributivas na propriedade e na renda, gerou êxodo rural, desemprego nos campos e nas cidades, marginalização urbana, exclusão social e econômica e desarticulação regional dos processos de desenvolvimento econômico" (SCHNEIDER; ESCHER, 2011, p. 204). O pequeno agricultor não consegue se desvencilhar dos interesses de mercado e, nesse embate, muitas vezes é despojado de seu habitat pela pujança extensiva do agronegócio. Em alguns casos, ele engrossa o contingente de trabalhadores temporários, "[...] pessoas que vagueiam pelo país para acompanhar os períodos de colheita, constituindo o trabalho sazonal [...]" (VENDRAMINI, 2007, p. 125). Nesse processo, ainda em curso, o pequeno produtor é descartado como agente produtivo 
e vivencia uma grave crise de identidade, tanto ao optar por viver no campo como clandestino no modo de produção, quanto ao ir para a cidade e se destituir de seu capital social. Apesar de o campo ser seu palco, a Revolução Verde exclui seus principais atores - ela institui a agricultura sem agricultor.

O modelo em referência instala uma dicotomia entre a agricultura familiar e 0 agronegócio. Esse último termo, em seu sentido amplo, designa toda atividade agropecuária com fins comerciais, incluindo tanto as atividades com fins comerciais da agricultura familiar quanto as desenvolvidas pelas grandes propriedades e corporações. Contudo, o termo carrega também a ideologia da modernização, do lucro, da utilização de altas tecnologias de produção, entre outras que não se concretizam como realidade nas pequenas propriedades, essas, portanto, não valorizadas segundo o prisma do agronegócio.

Apesar da falácia de que não se estabelece distinção, no Brasil particularmente, o modelo adotado se estrutura pela ideologia da modernização e prima pela vertente da hegemonia agrária. A agricultura familiar apresenta as características do conceito, mas não as da ideologia, daí a sua fragilidade. A expansão do capitalismo no campo atua como um "[...] rolo compressor, esmagando tudo no rumo à acumulação e à reprodução ampliada [...]" (OLIVEIRA, 2001, p. 194). A lei do agronegócio é a lei de mercado, à qual a agricultura familiar tem dificuldades de se adequar.

A força do trabalho se soma como mais uma variável diretamente afetada pelo atual modelo de desenvolvimento agrícola. O contexto econômico do campo despende cada vez menos força de trabalho, pois a "[...] exploração agropecuária tradicional, ao ser substituída pelas forças produtivas capitalistas, expandiu o produto do trabalho [...]" (CARVALHO; MARIN, 2011, p. 418), utilizando-se de menos trabalhadores. Tais braços se tornam também um importante slogan do agronegócio, que se vangloria de liberar mão de obra da agricultura para outros setores da economia, como a construção civil, por exemplo.

No entanto, essa liberação não acontece de forma democrática. O que ocorre são produtores sendo expropriados de seu meio de vida laboral, de sua identidade, de seu capital social, e passando, à própria revelia, a integrar o contingente humano regulador do preço a ser pago pela mercadoria "força de trabalho". Nesse prospecto, 
o sujeito é visto apenas como mercadoria, e a concepção filosófica do homem como construtor de sua história se confina ao campo da retórica.

O modelo atual de produção rural busca eficiência e produtividade, porém, essa eficiência é levada pronta ao campo, varrido para que o novo modelo se instaure. Não se cogita, pela ideologia de produção capitalista, viabilizar a eficiência do homem do campo, para que ele obtenha bons resultados de produtividade.

A lógica do agronegócio compromete também o desenvolvimento dos pequenos municípios (SOUZA; MEDEIROS, 2012), uma vez que os grandes produtores ignoram vínculos, seja em relação às terras, seja em relação às comunidades nas quais as atividades se desenvolvem. Os produtores, como grandes empresários, ignoram o drama dos sujeitos que se obrigam a abandonar suas terras para dar lugar aos canaviais, aos grãos, ao gado... Imperturbáveis, esses exploradores da terra adentram pequenas propriedades e dizimam comunidades inteiras.

Geralmente, os capitalistas do agronegócio exploram imensas extensões de terra, mas residem em terras distantes dali, e toda a renda obtida é levada para os grandes centros. Também é nos grandes centros que adquirem os insumos para a preparação do solo e para a manutenção do plantio. Assim, a riqueza gerada não é utilizada em benefício da comunidade local, sempre ignorada pelo agronegócio, que desencadeia, em consequência, problemas sociais nos municípios explorados, o que redunda no inchaço das cidades, no aumento da pobreza e da violência provocada pelo êxodo daqueles que são expulsos de seu pequeno sítio. Em municípios onde predomina a agricultura familiar caracterizada pela policultura, porém, há um giro maior das riquezas na localidade e maior absorção de mão de obra, contribuindo para um desenvolvimento harmônico entre o campo e a cidade.

Nesse meio, todos têm a ganhar em qualidade de vida e em cidadania. No entanto, o agronegócio produz mais alarde, uma vez que sua ideologia se processa em consonância com os setores dominantes transnacionais e se vende como o modelo que melhor representa o desenvolvimento local e nacional. Essa ideologia recebe o aval de sucessivos governos, uma vez que a larga produção representa riquezas, a que se curvam os que poderiam levar em conta o grande prejuízo socioeconômico que representa para as comunidades locais e para o desenvolvimento soberano da nação. 


\section{A tradição como qualidade remanescente}

Mediado por questões econômicas, o campo vem sofrendo severas transformações que interferem no seio da família do pequeno agricultor, em particular, e no meio rural, como um todo. A dinâmica da produção culmina em alterações que dizimam atividades tradicionalmente exercidas no campo. Vale lembrar que, para o caboclo imbuído da identidade rural, a agricultura traz representações que superam a variável econômica, pois, em seu bojo, resguardam-se manifestações da cultura e dos saberes empíricos que, de geração em geração, sobreviveram a intempéries, a guerras, a crises. Nos últimos tempos, porém, esse caboclo capitula diante da aclamada necessidade de modernização do campo.

Além da representação cultural, a agricultura tradicional também transita pelo viés econômico como meio de subsistência das famílias rurais, entretanto, com pouco valor de mercado. Esse é o maior empecilho à sobrevivência do homem no campo, pois, cada vez mais, o mercado se torna supremo diante dos ditames das leis que regem qualquer atividade produtiva, o que não é diferente no meio rural.

Mesmo atuando sob influência do mercado, traços tradicionais ainda podem ser observados nas comunidades rurais. Para o caboclo, a produção agrícola evidencia valor de uso, o que reforça sua característica cultural, sendo comum, por exemplo, a troca de produtos entre vizinhanças (GRISA; SCHNEIDER, 2008). Essa ligação solidária reflete também na posse da terra, condição que preserva um inestimável valor simbólico para os pequenos proprietários, diferentemente do mero valor comercial que representa para o latifúndio ou para aqueles que a utilizam apenas para dessa terra extrair lucro.

Possuir um pedaço de terra é um fator que assegura a pertença do sujeito à comunidade. É essa apropriação que estabelece a ligação do sujeito com seu grupo e pela qual são repassados os saberes tradicionais, que se perpetuam de geração em geração. As tradições solidárias existentes nas comunidades rurais se materializam na cooperação mútua, meio em que todos se irmanam nos momentos de desventura, de necessidades, em que não faltam braços para reforçar os mutirões. As características solidárias também se manifestam no âmbito religioso, em que festividades e comemorações envolvem a localidade, cujos habitantes trabalham unidos na condução desse viés cultural. A religiosidade é um importante fator simbólico para o fortalecimento da união da comunidade. Traços de 
solidariedade fortalecem a harmonia social, a integração e a união entre as famílias pertencentes à ela. São características de uma relação social personalizada, em que a preocupação com o bem comum se coloca acima dos interesses particulares.

A vivência peculiar em grupo, a cultura arraigada, a religiosidade, as tradições, a solidariedade, o trabalho... enriquecem o capital social do campo. O capital financeiro é consequência, porque a própria comunidade alimenta o desenvolvimento local. O termo é amplo, mas, em linhas gerais, pode ser entendido como o conjunto de representações que formam o bem supremo da comunidade, algo capaz de cimentar a união, a ajuda mútua e fortalecer a busca pelo bem comum (MILLÁN; GORDON, 2004).

Ao capital social do campo, resta o reconhecimento, uma vez que traz o estigma do atraso e da inferioridade diante da vida urbana. Escusado dizer que a ausência de complexidade das comunidades atua como um fator fundamental para a presença dos traços solidários e tradicionais; por conseguinte, quanto mais complexas as comunidades, menor a evidência dessas práticas. O capital social é mais forte e valorizado por aqueles sujeitos que manifestam mais integração com a comunidade e forte vínculo com a terra em que viveram seus pais, seus avós etc. É comum, nas comunidades rurais, haver um conglomerado de parentescos (OLIVEIRA; COSTA, 2005). Quando não, parentes ou compadrios são grandes conhecidos, havendo intenso contato entre eles, o que favorece e fortalece os laços solidários e o capital social.

Dada a forte ligação com a comunidade, quando os agricultores, imbuídos da identidade campesina e do capital social do campo, são forçados a deixar a terra em que vivem rumo às cidades ou nela permanecerem apenas como lócus de moradia enquanto vendem sua força de trabalho para terceiros, há uma perda de identidade, uma alienação causada pela ruptura de sua história. Ocorre perda de identidade não apenas daqueles que deixam sua comunidade, ou da terra se afastam como meio de subsistência, mas também da comunidade como um todo, pois os demais se sentem enfraquecidos como grupo e também sofrem com a perda e a possível descontinuidade dos traços de sua história, sempre construída em conjunto com seus pares.

A modernização também afeta o patrimônio dos saberes tradicionais do campo. Ela "[...] reverte uma tradição milenar dos agricultores, impondo o tempo 
como disciplinador do trabalho produtivo e como referência valorativa de moderno" (GEHLEN, 2004, p. 97). Promove, assim, uma dicotomia valorativa entre o moderno e o tradicional, esse último tido como ultrapassado e incapaz de obter bons resultados de produção, condenado a desaparecer, com total desconsideração do bem cultural que representa. Propõe-se, então, uma ruptura histórica. Tal visão representa a ideologia do agronegócio, em sua incansável busca por homogeneizar as formas de produção com base nos interesses industriais que produz, desde insumos até saberes científicos. Os saberes tradicionais, partindo do pressuposto dos interesses capitalistas no campo, estariam condenados ao ostracismo. Esses conhecimentos são condenados à ruptura antidemocrática, sem que seja considerada a sua reelaboração à luz do saber técnico.

Conhecimentos não são estáticos. O tradicional pode perfeitamente assimilar o novo e reestruturar sua utilização. No entanto, o saber científico é apresentado como única e legítima de conhecimento, afetando profundamente a identidade das comunidades e dos sujeitos rurais.

Conquanto resquícios de traços tradicionais ainda existam no campo, métodos produtivos modernos pouco a pouco os dominam; prevalecem em seu lugar a técnica e a sistematização do trabalho. No modelo capitalista, não cabe o trabalho como cultura, apenas como meio para a obtenção de mais valia. Deriva desse modelo o aumento do trabalho assalariado no campo, em detrimento do trabalho para o cultivo próprio, uma vez que a venda de força de trabalho é uma forma mais fácil de abstrair renda e participar com mais eficácia das relações de consumo. As características tradicionais do campo se esgotam em meio à introdução de técnicas modernas e ao esvaziamento humano patrocinado por fatores econômicos, sociais e culturais, em que predominam as leis de mercado.

\section{Influências do agronegócio nas ocupações do campo}

Historicamente, o homem do campo exerce a atividade agrícola como forma de subsistência, com técnicas e saberes tradicionais no cultivo da terra e com o pastoreio de animais. A modernização do setor agrícola, porém, domina as atividades das imensas propriedades, e as necessidades do campo e do campesino se transformam; a indigência se insere onde antes predominava a autossuficiência. 
Diante dos entraves econômicos ao cultivo da terra, as famílias dos pequenos agricultores tentam diversificar suas formas de obtenção de renda com atividades não diretamente ligadas à atividade agrícola, o que leva a agricultura a contribuir, cada vez com menos importância, para a renda de muitas famílias rurais. "Como a agricultura familiar/camponesa enfrenta dificuldades em seguir o ritmo produtivo acelerado do mercado, as famílias veem, na diversificação das fontes de ocupação e renda, a possibilidade de se inserirem no quadro econômico" (SOUZA, 2010, p. 3940).

As atividades não agrícolas apresentam peculiaridades, dentre elas, a falta de absorção de mão de obra na propriedade. Parte dos membros das famílias busca trabalho assalariado em propriedades maiores ou se desloca até os centros urbanos para encontrar ocupação. Pratica-se, também, a agricultura em tempo parcial, em que os agricultores dedicam parte do tempo a essa atividade e parte a outras. Ou, ainda, ocorrem o processamento e a comercialização nos centros urbanos de produtos oriundos da propriedade, como doces, queijos, verduras, aves, pequenos animais, artesanato, entre outros. As características dessa última sequência são relevantes para a agricultura familiar, pois, se embasada em uma estrutura eficiente, ela pode representar um salto na rentabilidade familiar, sem descaracterizar sua estrutura sociocultural. É a agricultura ousando um passo além do cultivo primário da terra.

Atividades desenvolvidas no campo buscam diversificar-se para preservar as condições do meio ambiente, oferecendo atividades como o turismo rural e a produção orgânica, as quais, por suas características, necessitam de estrutura e de recursos que a maioria dos pequenos agricultores não dispõe para financiar. Tais empreendimentos impõem onerosas mudanças e longo período para que o retorno financeiro apareça, o que os torna inviáveis para muitos agricultores sem potencial de investimento. São, portanto, atividades desenvolvidas, geralmente, por produtores capitalizados, não raramente ideólogos, que se instalam nas comunidades para iniciarem tal prática. São aqueles que possuem reservas financeiras para a própria manutenção e aguardam o retorno que pode demorar anos (SOUZA, 2010).

Paradoxalmente, esse segmento demanda farta mão de obra, algo abundante nas famílias rurais. Nele, a agricultura familiar tem potencial para obter bons 
resultados de produção e, exatamente pela mão de obra de que dispõe, leva vantagem em relação à propriedade patronal. O empreendimento agroecológico é uma alternativa eficaz para a agricultura familiar, porém, aos pequenos agricultores, faltam recursos para financiá-lo.

A pluriatividade promove

[...] uma articulação entre a agricultura e os demais setores econômicos, em um contexto territorial que já foi agrícola e rural, passando cada vez mais a ser caracterizado pela presença de diversos ramos de atividade, com exceção das áreas mais atrasadas e mais pobres. (BALSADI, 2001, p. 159)

Em regiões menos valorizadas, constata-se o predomínio da agricultura nos moldes tradicionais, uma vez que a relação com o meio urbano com potencial de consumo, principal foco das atividades não agrícolas, fica dificultada.

No entanto, muitas das atividades não agrícolas, desenvolvidas de forma precária, "[...] são frequentemente caracterizadas como de baixa produtividade e produtoras de bens de má qualidade, condenadas a desaparecer com o crescimento da economia" (NEY; HOFFMANN, 2009, p. 150). As atividades em referência não representam

uma ampliação das oportunidades de trabalho para os membros da família, tornados supérfluos pelo progresso técnico, mas sim uma chance de sobrevivência, em geral precária, para produtores sem acesso ao progresso técnico, à terra suficiente, ao crédito etc. (BUAINAIN; ROMEIRO; GUANZIROLI, 2003, p. 316)

Atividades não agrícolas comumente representam uma alternativa sem planejamento para a falta de trabalho no campo. Da maneira como são exercidas, não atuam como opção concreta para os problemas socioeconômicos vivenciados pelas comunidades rurais; mesmo porque essas alternativas se encontram na própria agricultura familiar, cujo potencial de geração de ocupação e renda "[...] está longe de ser plenamente utilizado [...]" (BUAINAIN; ROMEIRO; GUANZIROLI, 2003, p. 317).

As atividades não agrícolas possuem um vasto campo para se desenvolver, mas devem ser privilegiadas aquelas geradas "[...] mediante apoio à agricultura familiar" (BUAINAIN; ROMEIRO; GUANZIROLI, 2003, p. 317), uma vez que é nesse segmento, que se encontra o verdadeiro potencial do campo. $O$ desenvolvimento de uma agricultura familiar forte contribui para solucionar problemas de ordem 
econômica, social e ambiental, pois é capaz de gerar divisas e absorver grande parte da mão de obra que hoje segue para as periferias das grandes cidades.

As comunidades rurais interagem com a estrutura capitalista, pois não lhes resta alternativa para sobreviver dignamente, caso não se submetam à engrenagem que lhes é imposta. A mercantilização dos produtos do campo afeta as relações sociais, culturais, econômicas e transforma o sujeito e suas formas de reprodução. "Isso se expressa na diversidade e na heterogeneidade das formas sociais rurais, bem como das relações de produção, circulação e consumo instituídas, enquanto processos imersos nas contradições das economias de mercado" (SCHNEIDER; ESCHER, 2011, p. 206-207).

O sujeito do campo, em tal relação, não importa se favorável ou não ao pequeno produtor, depende de diversos fatores, dentre eles, dos recursos financeiros de que disponha para investir, assim como de sua capacidade empreendedora. Destaque-se que a lógica do caboclo não é mercantil (GEHLEN, 2004); tradicionalmente, sua produção se resume a mero valor de uso, e os parcos conhecimentos de que dispõe apresentam-se como obstáculo intransponível à assimilação dos novos paradigmas que movem hoje a economia.

Uma das formas de tornar a interação com o agronegócio mais favorável seriam as associações dos produtores. Como enfatizam Marx e Engels (1959 apud HABERMAS, 2000):

Só quando o homem individual real absorver em si o cidadão abstrato [...], quando organizar e reconhecer suas forces propres como forças sociais, e, por conseguinte, não separar mais de si a força social como força política, só então se realizará a emancipação humana. (p. 89)

No entanto, desconhecem-se formas associativistas como práticas correntes nas comunidades tradicionais do campo. A solidariedade dos campesinos não logra integrar-se como massa política; isso pode ser explicado pelo fato de que, talvez, a racionalidade, e não a solidariedade, atue para mover os sujeitos rumo à cooperação (COSTA et al, 2010), ou, ainda, pelo fato de a solidariedade se basear "[...] em um senso de perigo comum, e não em uma pessoa comum ou em um poder compartilhado" (DUSSEL, 2011, p. 139), não significando, portanto, "[...] compartilhar uma crença comum ou uma meta comum" (DUSSEL, 2011, p. 139). Dessa última perspectiva, a solidariedade se apresenta como um mecanismo capaz de superar 
obstáculos pragmáticos imediatos e/ou em demais situações da vida cotidiana, sem conexão com a elaboração de um projeto de futuro.

A desconfiança atua como outro empecilho ao associativismo, uma vez que muitos agricultores "[...] desconfiam dos benefícios que tais práticas associativistas possam proporcionar e interpretam o fracasso de outras tentativas de associativismo como algo que tenda a se perpetuar, o que dificulta a formação de associações ou cooperativas" (FERREIRA et al., 2009, p. 783). Dessa forma, são "[...] poucos os produtores que se arriscam a participar da organização de uma associação ou cooperativa, enquanto a maioria espera a concretização dos resultados, para, posteriormente, tornarem-se membros" (FERREIRA et al., 2009, p. 783). Acredita-se, assim, que o caminho para a emancipação do campo como lócus de produção e vida deve ser despertado por meio da conscientização, de sacudir essa inércia política.

As estratégias de sobrevivência adotadas pelas famílias rurais são também múltiplas, de acordo com a capacidade de financiamento, localização geográfica, entre outros fatores. Muitas vezes, as alternativas se dispõem ao acaso, apenas como medidas paliativas para sanar necessidades emergenciais de sobrevivência, geralmente, mediante venda da força de trabalho.

Quando se instalam condições favoráveis, em regime de exceção, e não como regra, constata-se a possibilidade de se desenvolverem atividades organizadas e planejadas, viabilizando que a cadeia de produção e/ou serviços se processe. Para tal planejamento, porém, variáveis complicadoras devem ser consideradas, como a logística da distribuição da produção. Nesse sentido, os agricultores são prejudicados, porque, geralmente, se encontram em condições desfavoráveis com relação à logística do escoamento da produção.

O potencial da força de trabalho existente no campo deveria merecer melhor utilização em atividades integradas e planejadas. Vários segmentos de atividades, se encadeados, teriam condições de produzir desenvolvimento para as comunidades com base nas características presentes em cada uma delas, sem, é claro, deixar de focar a agricultura familiar, linha mestra de toda e qualquer política que tenha por meta reestruturar o campo como lócus de produção e de vida. 


\section{Educação como complemento à emancipação}

A educação para o meio rural, em sua gênese, sofre influência da oligarquia agrária, sempre privilegiando a manutenção do status quo. Para romper o referido círculo, na década de 1990, ganhou força uma luta: Por uma educação do campo, germinada no interior dos movimentos sociais, em prol de uma educação em favor dos interesses dos campesinos, em uma luta atenta para a realidade e para as necessidades do campo (SOUZA, 2010). Esse projeto foi assimilado pelas forças políticas, que passaram a garantir legalmente para o campo um conceito educacional, com a peculiaridade, com a qualidade que ele merece e de que necessita. Apesar de ainda estar em fase inicial, ele representa um importante passo para uma ação educativa no campo, conectada às necessidades do meio rural, e que se desenvolve em consonância com o contexto social e econômico com o qual interage.

A importância da educação para o desenvolvimento do campo é inquestionável, pois "[...] se destaca como o fator que explica, individualmente, maior parcela das disparidades de renda do trabalho no meio rural, com efeito, substancialmente maior do que o de todos os outros fatores" (NEY; HOFFMANN, 2009 , p. 174), como a distribuição de terras, por exemplo. Ela representa uma importante variável para a qualidade das formas de obtenção de renda que o trabalhador do campo pode desenvolver.

O favorecimento à formação política e o fomento aos movimentos sociais se destacam como características, como mecanismos essenciais para que o campesino reconheça e requisite seus direitos, munido ideologicamente. Assim, a luta entre esses pequenos produtores e as forças capitalistas poderão confrontar-se em níveis menos desiguais, com a possibilidade de os campesinos se organizarem para 0 atendimento a suas proposições. Imbuídos de uma consciência campesina, a educação privilegia a emancipação do sujeito rural, uma vez que no

processo de emancipação, a liberdade da consciência é um importante passo. Consciente de si e das contradições que o cercam, o campesino terá condições de se mobilizar para conquistar também sua liberdade econômica e se realizar enquanto sujeito emancipado. (SOUZA; GABRIEL, 2012, p. 239)

Indubitável faz-se a constatação de que a educação é indispensável para as perspectivas de desenvolvimento; contudo, o peso efetivo na geração imediata de renda varia de acordo com a complexidade dos meios produtivos. Dentre os 
produtores mais estruturados, a educação contribui com mais expressivo peso que para aqueles menos desenvolvidos (FEIJÓ, 2010). A educação também exerce menos impacto na agricultura que na indústria e no setor de serviços (NEY; HOFFMANN, 2009). Essa condição se reflete, sobretudo, na agricultura familiar que, por utilizar técnicas rudimentares, não exige sujeitos com mão de obra qualificada. Impõe-se uma transformação desse cenário, para o qual a educação se coloque como um elo fundamental, a fim de aprimorar a qualidade da produção da agricultura familiar para um patamar de excelência em resultados, o que não ocorre sem a colaboração de um campesinato engajado, munido da ideologia de classe e sabedor de suas potencialidades como agente produtivo e político, ativo na sociedade.

Em seara de atividades agrícolas tradicionais e precárias, a educação não representa um fator determinante imediato. Nas atividades não agrícolas, "[...] o desempenho educacional é considerado um condicionante importantíssimo [...]" (NEY; HOFFMANN, 2009, p. 148), uma vez que, quanto mais instruído for o sujeito que circula em tais âmbitos de atividades, melhores condições ele terá para se destacar como prestador de serviços ou como produtor diferenciado. Assim, "[...] a expansão das atividades não agrícolas tende a aumentar o efeito da educação na renda" (NEY; HOFFMANN, 2009, p. 175). A educação, no momento em que estabelece relação com a melhoria na renda do campesino, passa a fortalecer a diversidade produtiva no meio rural e a capitalizar os sujeitos para aliar a criatividade ao empreendedorismo.

A prática educativa, para assumir esse caráter emancipador do sujeito rural, carece de fundamentos filosóficos, necessita libertar-se da condição da subserviência e da dominação. Subsídios podem ser encontrados em Gramsci, na filosofia da práxis, que se preocupa com os grupos subalternos e busca formar neles pensadores para a elaboração teórica e política de resistência.

À filosofia da libertação, originária na América Latina, interessa, "[...] acima de tudo, a novidade e a descoberta científica, mas não como um fim, e sim como um elemento do processo de autorrealização da dignidade da pessoa" (DUSSEL, 2011, p. 65). Interessa, também, a "[...] penetração do Outro na Totalidade vigente" (DUSSEL, 2011, p. 24), e está situada "[...] no contexto da vida prática concreta, dentro do comprometimento e solidariedade com o oprimido [...]" (DUSSEL, 2011, p. 
126). Elementos filosóficos como esses são intrínsecos à realidade e às necessidades do sujeito rural e da agricultura familiar. São princípios que a pedagogia deve considerar como auxílio para (re)construir a emancipação do campo.

Embora fundamental para o desenvolvimento do campo e mesmo dispondo de condições de amparo legal para sua implantação, a educação no meio rural ainda está longe de atingir patamar satisfatório de qualidade. Muitos ainda são os empecilhos que se apresentam, como a dificuldade de transporte, as intempéries, a insistente e desarticulada adaptação de currículos, além de muitos outros agentes que dificultam o acesso à educação no campo e que colocam esse campesino em condições distantes do ideal desejado. Resta ao trabalhador a persistência nessa luta, para que tenha acesso a esse importante bem social, fator fundamental para que esse homem do campo se torne sujeito atuante politicamente e compartilhe do desenvolvimento trazido pela modernização das atividades rurais.

\section{Considerações finais}

Múltiplas possibilidades se abrem diante do homem do campo que cultiva a pequena propriedade. Nichos de mercado, diferenciação de produtos, agregação de valor, práticas agroecológicas, atividades não agrícolas, entre outras, representam alternativas, cujo sucesso se condiciona por fatores que exigem criatividade e recursos movidos por iniciativas individuais. Infelizmente, toda essa estrutura carece também do apoio de uma política integrada, para que o campesino possa enfrentar o monopólio dos exploradores da monocultura.

O desenvolvimento de tais atividades familiares, diante da inexistência de apoio governamental, não logra atingir o crescimento de atividades rentáveis e promissoras. Somente, destaque-se, com o amparo do Estado, será possível equalizar tal distorção. Sem que haja o estímulo público para esse desenvolvimento, o pequeno agricultor se deixa dominar pelo desinteresse do cultivo do campo, e a deserção, assim, se consuma. Resta, porém, a esperança de que os sujeitos rurais se mobilizem para lutar por oportunidades de desenvolver a potencialidade da agricultura familiar e a cadeia de atividades que a envolve ou que com ela se identifica. Um importante amparo reside na educação. É nela, que os atores rurais encontrarão fomento ideológico e político, cimento para os movimentos sociais. 
Somente organizados e conscientes de sua condição de classe de trabalhadores do campo, os sujeitos rurais terão força para buscar amparo político e revigorarem a demanda produtiva das comunidades rurais.

Imbuídos do desejo de mudança, de transformação, impõe-se que o papel da educação vá além da sua função social de apenas alfabetizar. É preciso desenvolver um processo educacional que busque fortalecer a cidadania, a democracia, a justiça e a solidariedade, a fim de que todos os trabalhadores, independentemente de classe social, setor, ou região, tomem posse, de fato, do lugar que lhes compete na sociedade, qual seja, o da oportunidade de participar do verdadeiro progresso social como cidadão consciente de seu destino na comunidade em que vive.

\section{Referências bibliográficas}

ANDRADES, Thiago Oliveira de; GANIMI, Rosângela Nasser. Revolução verde e a apropriação capitalista. Centro de Ensino Superior de Juiz de Fora. CES Revista, v. 21, p. 43-56, 2007.

BALSADI, Otavio Valentim. Mudanças no meio rural e desafios para o desenvolvimento sustentável. São Paulo em Perspectiva, v. 15, n. 1, p. 155-165, jan 2001.

BUAINAIN, Antônio Márcio; ROMEIRO, Ademar R.; GUANZIROLI, Carlos. Agricultura familiar e o novo mundo rural. Sociologias, ano 5, n. 10, p. 312-347, juldez 2003.

CARVALHO, Simone Pereira de; MARIN, Joel Orlando Bevilaqua. Agricultura familiar e agroindústria canavieira: impasses sociais. Revista de Economia e Sociologia Rural, v. 49, n. 3, p. 681-707, jul-set 2011.

COSTA, Luiz Fernandes da et al. Democracia e desenvolvimento local em assentamentos rurais. Interações, v. 11, n. 2, p. 161-169, jul-dez 2010.

DUSSEL, Enrique. Filosofia da libertação: crítica à ideologia da libertação. 4ㄹaed. São Paulo: Paulus, 2011.

FEIJÓ, Ricardo Luis Chaves. O efeito do título de propriedade da terra na determinação da renda rural. Revista de Economia e Sociologia Rural, v. 48, n. 4, p. 673-707, out-dez 2010.

FERREIRA, Patrícia Aparecida et al. Estado e agricultores familiares: uma análise interpretativa sobre o desenvolvimento rural no Sul de Minas Gerais. Revista de Economia e Sociologia Rural, v. 47, n. 3, p. 767-792, jul-set 2009.

GEHLEN, Ivaldo. Políticas públicas e desenvolvimento social rural. São Paulo em Perspectiva, v. 18, n. 2, p. 97-103, jun 2004. 
GRISA, Catia; SCHNEIDER, Sergio. "Plantar pro gasto": a importância do autoconsumo entre famílias de agricultores do Rio Grande do Sul. Revista de Economia e Sociologia Rural, v. 46, n. 2, p. 481-515, abr-jun 2008.

HABERMAS, Jürgen. O discurso filosófico da modernidade: doze lições. São Paulo: Martins Fontes, 2000. (Coleção Tópicos)

MILLÁN, René; GORDON, Sara. Capital social: una lectura de tres perspectivas clásicas. Revista Mexicana de Sociología, ano 66, n. 4, p. 711-747, out-dez 2004.

NEY, Marlon Gomes; HOFFMANN, Rodolfo. Educação, concentração fundiária e desigualdade de rendimentos no meio rural brasileiro. Revista de Economia e Sociologia Rural, v. 47, n. 1, p. 147-182, jan-mar 2009.

OLIVEIRA, Alecio Rodrigues de; COSTA, Vera Mariza Henriques de Miranda. Desenvolvimento territorial: sociabilidade, solidariedade e capital social. In: SIMPÓSIO NACIONAL DE GEOGRAFIA AGRÁRIA, 3., 2005, Presidente Prudente. Anais eletrônicos... Presidente Prudente: UNESP, 2005. Disponível em: <http://www2.fct.unesp.br/nera/publicacoes/singa2005/Trabalhos/Artigos/Alecio\%20 Rodrigues\%20de\%200liveira.pdf>. Acesso em: 5 ago. 2016.

OLIVEIRA, Ariovaldo Umbelino de. A longa marcha do campesinato brasileiro: movimentos sociais, conflitos e Reforma Agrária. Estudos Avançados, v. 15, n. 43, p. 185-206, dez 2001.

PERESTRELO, José Paulo Pires; MARTINS, Ignez Salas. Modernização rural: transformações econômicas e suas implicações demográficas, epidemiológicas e nutricionais nos municípios de Monteiro Lobato e Santo Antônio do Pinhal. Saúde e Sociedade, v. 12, n. 2, p. 38-55, jul-dez 2003.

SCHNEIDER, Sergio; ESCHER, Fabiano. A contribuição de Karl Polanyi para a sociologia do desenvolvimento rural. Sociologias, v. 13, n. 27, p. 180-219, mai-ago 2011.

SOUZA, Reginaldo Motta de. Educação do campo: a bandeira política que movimenta o meio rural. 2010. Monografia (Graduação em Pedagogia) Universidade Estadual do Norte do Paraná, Jacarezinho, 2010.

; GABRIEL, Fábio Antônio. Educação do Campo: a filosofia como práxis educativa. In: BATTESTIN, Cláudia; GABRIEL, Fábio Antônio (Orgs.). Filosofia e educação: um diálogo entre os saberes na contemporaneidade. Rio de Janeiro: Multifoco, 2012. p. 235-252.

; MEDEIROS, Suzana Cláudia de Oliveira. Educação do Campo: do conceito e da teoria à realidade e à prática. Oficina realizada na Semana Pedagógica, jul. 2012. SEED/NRE Jacarezinho. Santo Antônio da Platina, 2012.

VENDRAMINI, Célia Regina. Educação e trabalho: reflexões em torno dos movimentos sociais do campo. Cadernos CEDES, v. 27, n. 72, p. 121-135, mai-ago 2007. 